\title{
DE LA POR A L'ESPEGTACLE Notes sobre política, cultura i cinema en la Transició espanyola
}

\author{
Manuel Alcaraz Ramos
}

Universitat d'Alacant

Probablement, El precio de la transición, de Gregorio Morán, publicada el 1991, va ser la primera obra de gran honestedat i amb certa ambició en la qual es va revisar, no sense amargor, la versió autocomplaent i acrítica que s'havia anat construint de la Transició. L'autor concloïa que «para la cultura la transición no existió; ni como reforma ni como ruptura», i matisava: «los diversos mundos culturales españoles llegaron a la transición unos —los más tradicionalescon cierto desamparo y angustia, otros con arrollador entusiasmo [...]. La transición lo único que hizo fue convertir la pobreza provocada por esos años oscuros, explicables por razones históricas, en espectáculo»'. Des del meu punt de vista, Gregorio Morán encertava la descripció dels símptomes i errava el diagnòstic. Intentar explicar aquesta paradoxa ens pot servir per a mirar de fer una anàlisi de conjunt del rerefons políticocultural de la Transició, context indispensable per a qualsevol reflexió sobre el cinema en aquest període.

Si errava el diagnòstic és perquè partia d'una hipòtesi improbable: la Transició cultural hauria d'haver consistit en una restauració dels valors i projectes, tan valuosos, tallats per l'espasa del franquisme. Però, segons Gregorio Morán, això es no va voler fer, i aquesta actitud va constituir una de les renúncies - per covardia, ignorància o imposició- dels protagonistes de la Transició. Per descomptat que aquest tall es va produir i va persistir, però és difícil imaginar com es podia suturar tant esquinçament, quina voluntat podia posar fi a aquesta escissió del temps. Noteu, incidentalment, que la tesi és molt poc aplicable al terreny cinematogràfic. I noteu també que, imperceptiblement i contradictòriament, en aquesta matèria l'autor necessita uns quants motors preferents, uns quants dissenyadors intel-ligents que pilotaren la Transició i que, per això, estaven en condicions de pactar, renunciar o imposar, fins i tot en matèria cultural. Però aquesta visió és pura ideologia, translació a la totalitat social d'un mite, precisament del que ara intenten desprendre's els historiadors i analistes per a retornar al poble el seu caràcter central en el procés i per a poder rebatre els paranys que intenten ignorar la part d'improvisació que hi va haver en aquell moment. No seria millor, fins i tot admetent els errors irreparables i les més mesquines traïcions, acceptar que la cultura

1 MORÁN, G. El precio de la transición. Planeta, Barcelona, 1991, pàg. 231 i 204. 
transitava ja per altres camins, més amples que el que la nostàlgia ens permet comprendre?; que, per exemple, la cultura no podia ser tan literària com en etapes prefranquistes?

I no obstant això, en efecte, és més que plausible acceptar la Transició en la cultura com un «espectacle». O com una festa, si es prefereix. Amb la condició de mantenir-nos en el nivell descriptiu i sense obstinar-nos ni a celebrar ni a anatematitzar aquests conceptes. I aprecianthi el que hi va haver d'organitzat i d'improvisat, de reflexiu i d'irracional, d'oportunista i de militant. En definitiva: em sembla lícit entendre les grans maniobres culturals de la Transició com a metàfora mateixa d'aquest temps, com a política viscuda d'una altra manera. O, més ben dit, reclamaré per a aquest temps una doble Transició, necessàriament complicada i amb nombrosos vincles entre els dos plans en presència: l'estrictament polític, en trànsit de canviar les institucions, i el cultural, que s'obri sense parar compte en límits preestablits, amb la irradiació d'estètiques que ens suggereixen que hi havia molt de projecte encapsulat, ajornat -en relació amb experiències europees, per exemple-, que desembocaran en aquest espectacle fundat sobre les cendres de la dictadura. Una cultura, doncs, postfranquista, i, ateses les pressions anteriors, contrafranquista, encara que no sempre antifranquista.

Probablement, com hem indicat, les fases «política» i «cultural» no van estar sempre temporalment compassades, però durant els anys previs a la mort de Franco es constata el creixement d'espais de llibertat $\mathrm{O}$, almenys, d'espais crítics protagonitzats per intel-lectuals, creadors o, en molts casos, per persones sense cap especialització o vocació especial, però amb afanys d'alimentar alguna flama que animara l'Espanya grisa ${ }^{2}$. Serà a través d'experiències culturals com podran adquirir reconeixement, en àmbits més amplis que els propis i originaris: grups obrers, veïnals, juvenils, feministes, etc. Tot això fructificarà en formes d'oposició política i revestirà en la mateixa Transició política un cert vernís culte, al mateix temps que contribuirà a trencar 0 , almenys, a alimentar fissures en el gran patrimoni axiològic del règim: la por. En definitiva, aquest fenomen s'ha d'inscriure en una dinàmica més àmplia, en aquest protagonisme col·lectiu de la Transició al qual he al·ludit. Així, l'espectacle era la sacsejada necessària per a alliberar-se de la por. I, com a festa, un ritual d'exorcisme contra el desfici.

Perquè crec que Santos Juliá té raó quan defineix el món de la Transició com «un món en moviment, caracteritzat per la presència de desenes de possibles actors a la recerca d'un espai propi en el qual concorrien, s'enfrontaven o es coalitzaven persones de diferents generacions, amb biografies polítiques molt diferents, carregades o lleugeres d'experiències tant de poder com d'oposició, sobre un fons de crisi política aguditzada per l'evident final del cicle del desenvolupament econòmic»; per a concloure: «No, no fue una masa despolitizada que dejaba que a sus espaldas unas elites desaprensivas pactaran el futuro, lo que imprimió el carácter a aquel tiempo de ebullición e incertidumbre»³. En aquest àmbit no em sembla desgavellada la hipòtesi que la cultura —una cultura compartida i definida per contrast amb la que hi havia - va tenir el paper de ciment davant d'algunes dispersions inevitables i va servir per a organitzar alguns dels relats bàsics de la Transició. Insistisc: no sense contradiccions, no sense fugides cap a destinacions incertes, no sense molt de voluntarisme desconcertant. Des

2 TUSSELL, J. Historia de España en el siglo XX. 4. La transición democrática y el gobierno socialista. Taurus, Madrid, 2007, pàg. 237 i seg. SOTO CARMONA, A. «Nosotros estuvimos allí». El protagonismo de la sociedad durante la Transición. En: AA.V.: Tiempo de Transición (1975-1982. Fundación Pablo Iglesias, Madrid, 2007, pàg. 47 i seg.

3 JULIÁ, S. Tiempo de luchar, aprender y pactar. En: AA.VV., 2007: 22. 
d'aquesta perspectiva, un paper peculiar del cinema va ser —encara que no en solitari- el de posar de manifest que els temps de separació radical i rígida, ideològica i fàctica, entre una cultura d'elit i una altra de popular, entre una de qualitat i una altra de subordinada, s'havien acabat. Amb independència dels continguts i de la voluntat —o de l'habilitat- de molts dels seus creadors, aquesta va ser l'aportació més important del cinema a la democràcia renaixent. Perquè el cinema, com cap altra manifestació cultural, va ser vivència de la democràcia.

I és que de molt poc serveix llançar mirades cap a temps llunyans si no s'aprecia que els canvis culturals en l'Espanya dels setanta eren de tal envergadura, que es podien considerar estructurals, fins i tot en una dimensió antropològica. Abans de prosseguir l'argumentació, cal fer algunes excepcions: no seria lícit veure-hi una espècie de resultat de bones intencions del tardofranquisme, segons prediquen certs revisionistes enyoradissos del règim, sinó, al revés, un senyal de derrota del sistema autoritari, incapaç de mantenir-se fidel als seus principis, i obligat a cedir davant de la inevitable força de les contradiccions que construïa. Els exemples són evidents: en les causes i en els resultats de l'emigració —interior i exterior- o del turisme podem apreciar com les promeses del franquisme es resolien, necessàriament, en transformacions no volgudes, amb un potencial crític que generava alteracions en els valors i, per tant, en els supòsits culturals que interpretaven la vida i la política en aquesta etapa.

Això no va comportar, és clar, que l'esfera pública ${ }^{4}$ del règim admetera passivament els canvis, ni que la seua cultura política no maldara per perpetuar-se encaixada en els vells clixés del nacionalcatolicisme. Però tot això no podia sinó transcórrer com un viatge per paisatges irreals, com si els vells jerarques s'hagueren reclòs per a celebrar infinitament el seu pas pel món en el NO-DO, aquell descriptor simbòlic d'un univers pautat i cíclic, delerós $d^{\prime}$ 'immutabilitat, en què va ambicionar convertir-se el franquisme ${ }^{5}$. I no és casualitat que l'extinció mateixa del NO-DO fóra un contrasímbol summament eficaç de l'època, com si, quan els espanyols-espectadors eixien d'una sala de projecció en la qual ja no s'inauguraven pantans ni els productors feien exercicis gimnàstics, els carrers i les avingudes foren més grans i les places més acollidores.

Tampoc és que es puga parlar d'una transformació sobtada dels valors dominants ni d'una caiguda fulgurant dels que el règim havia triat com a mesura de la seua eficàcia recorde, una altra vegada, el terror com a ultima ratio del procés polític. Al cap i a la fi, com tothom sap, el desig de llibertat era perfectament compatible amb el d'estabilitat, amb el desig d'evitar la deriva cap l'infaust llibertinatge: les enquestes indiquen que el 1975, la «pau» era el valor preponderant, molt per davant de la «democràcia», la «llibertat» o la «justícia». O, dit d'una altra manera: la Transició era volguda sempre que la llibertat i la democràcia s'aconseguiren sense alterar l'espantosa concepció que el franquisme havia difós sobre la conservació de la pau; i la Transició va ser possible en la mesura que moltes pedagogies van fer apreciar a la majoria que aquesta pau, en sentit perdurable, només seria possible amb llibertat i democràcia. Encara que, lògicament, això no es va poder realitzar

4 REIG CRUAÑES, J. Identificación y alienación. La cultura política en el tardofranquismo. Universitat de València, 2007. Passim.

5 TRANCHE, R. i SÁNCHEZ-BIOSCA, V. NO-DO, el tiempo y la memoria. Cátedra/Filmoteca Espanyola, 2a ed., Madrid, 2001. Passim.

6 AGUILAR FERNÁNDEZ, P. Cultura política, consum cultural i memòria durant la Transició. En: AA.VV., 2007: 86 i seg. 
sense atiar altres inseguretats. Descriure el conjunt d'alternatives en aquest procés, i també les seues desviacions, equival a fer la narració completa de la Transició. I, una vegada més, des d'aquesta perspectiva, la cultura exigeix enfocaments preferents i renovats.

En definitiva, i més enllà dels detalls, l'espectacle cultural de la Transició es va representar sobre l'escenari dels canvis que hem apuntat. Així, la societat que la democràcia arrancaria de l'abraçada del franquisme era una societat molt més laica que no es podia presumir: la cultura catòlica va tendir cap a la irrellevància perquè l'església es va adaptar a la nova situació política —no sense cobrar peatge-, però va ser incapaç d'adaptar-se a l'evolució de la cultura... Una mancança de la qual encara es ressent, en termes d'incomprensió del mitjà i que, per cert, transmet a la dreta política, privada de fonts autònomes d'elaboració ideològica amb arrels profundes. Igualment, era una societat en la qual les dones continuaven responent a pautes de subordinació, però no a l'esgarrifosa relegació de dècades anteriors: començaven a incorporar-se al mercat de treball i elaboraran discursos feministes que seran una part consubstancial de la cultura de la Transició. La societat espanyola era ja eminentment urbana, amb tot el que això significava de noves relacions interpersonals fluides, de comprensió de la variabilitat i de la pluralitat. Com a plural s'anava descobrint des del punt de vista de lingüístic i nacionalitari, enfront de l'exclusivisme uniformador del règim. De la mateixa manera, la societat espanyola havia avançat extraordinàriament en el nivell d'alfabetització i els fills de les capes mitjanes es preparaven per al boom universitari. Cadascun d'aquests aspectes requeriria múltiples aclariments, però és el conjunt el que ens parla, en aquest moment de crisi econòmica i política, d'una societat alterada, un factor infinitament més important que qualsevol suma de creadors prestigiosos, que qualsevol nòmina d'obres de referència, que qualsevol política cultural.

Serà tota aquesta suma de canvis la que provocarà el final de l'escissió entre cultura d'elit versus cultura popular-tradicional. Arguments i formes culturals que tenien un significat enorme per a milions d'espanyols i espanyoles van lliscar, en pocs lustres, cap a la categoria anecdòtica de folklòric; mostres d'exclusivisme es van haver d'obrir i van irrompre altres espècies d'expressió cultural inassimilables als esquemes centrats en aquest dualisme rígid. En realitat, la combinació dels elements apuntats, més la penetració enèrgica i imparable de la televisió com a gran igualador dels missatges, indiquen que la Transició es va produir quan Espanya estava madura perquè es poguera parlar de cultura de masses. Res de més apropiat, doncs, per al gran espectacle de masses, ple de dramatisme, que va ser la Transició.

Des d'aquesta òptica, el cinema és el millor difusor de l'estat de coses, a part de la mateixa televisió, ${ }^{8}$ de la qual, si bé no disposem de dades d'audiència absolutament fiables, no hi ha

7 Aquesta és una qüestió interessant en la qual, però, no ens podem aturar: el mateix concepte significava un canvi respecte del que era habitual en el franquisme, que solia qualificar la política cultural amb l'adjectiu «popular» o, simptomàticament, unir-la a les polítiques turístiques. Potser com un altre reflex de tot això, de la novetat mateixa de les polítiques culturals, la falta de projectes coherents i la inestabilitat va ser la nota preponderant: com s'ha recordat, en els cinc anys de governs de la UCD hi va haver sis directors generals de Cinematografia. TUSSELL, J., 2007: 241.

8 El paper de la TVE en la Transició encara no ha sigut estudiat definitivament i, sovint, els treballs existents s'han centrat més en els aspectes essencialment informatius - més directament lligats a la política- que en els genèricament culturals, encara que hi haja referències interessants als possibles significats més o menys subliminals de sèries que van triomfar en aquesta època. Un comentari general i referències bibliogràfiques particulars en: AGUILAR FERNÁNDEZ, P., 2007: 100 i seg. Els programes amb més audiència es poden veure en la pàg. 118. 
dubte que estava molt present en els hàbits de gran part de les famílies espanyoles —que ja tenien set milions de televisors-, i formava imaginaris i llenguatges, barrejava informació amb diversió i promovia insensiblement una educació audiovisual accelerada?. És plausible pensar que el contínuum que s'establia en aquell moment entre el cinema i la televisió era més marcat que el d'èpoques posteriors: probablement la concepció de la televisió com un cinema en petit estava àmpliament acceptada. En aquest cas, I'avanç de la televisió com un gran artefacte domesticocultural facilitaria la labor didàctica i simbòlica del cinema. Però, alhora, la diferència hi era i s'apreciava, i per aquesta raó s'atribuïa al cinema un cert plus de prestigi cultural i s'inscrivia en un àmbit de sociabilitat diferent. A tot això, com a referent global, podem sumar la valoració eticoestètica particular que alguns grups intel-lectualment dirigents van fer del cinema.

En aquest esquema, parlar de cinema i Transició agrupa una realitat que no es pot esgotar en les produccions espanyoles ${ }^{10} \mathrm{i}$, encara menys, en les més selectes. Tampoc es pot negligir l'endarreriment —relatiu i absolut- de les indústries culturals a Espanya, en part ofegades pel mateix clima autoritari. I caldrà considerar la penetració del cinema forà: el que era demanat o el que era imposat als espectadors. I, per descomptat, qualsevol anàlisi que se centre massa en el cinema polític o ideològic, o que done una preferència excessiva al documental, deixarà de banda una bona part del significat últim del cinema en la trama políticocultural de la Transició.

lés que el cinema tindrà la funció essencial de posar en pràctica una didàctica de la llibertat, d'una llibertat quotidiana, autoexplícita, que es justifica per si mateixa, sense necessitat de recórrer en cada moment a discursos subsidiaris de legitimació. Serà prioritàriament en el cinema on s'aprecie el declivi mateix de la censura, des del Decret d'1 d'abril de 1977,11 tan tímid, fins a la implantació de la llibertat d'expressió com a dret fonamental en la Constitució i el seu desenvolupament posterior ${ }^{12}$. I en el cinema es verificaran els límits efectius d'aquesta possible llibertat, amb algun cas axiomàtic, com El crimen de Cuenca, de Pilar Miró.

No és casual que l'erotisme, la sexualitat, es convertiren en la pedra de toc del procés:13 per les mateixes característiques del mitjà cinematogràfic, la llibertat s'associarà molt més

9 Aquesta idea, que associa el desenvolupament de la televisió amb la constitució de públics de masses que fan inviable la distinció clàssica en dos tipus de cultura, alta i baixa, he intentat aplicar-la a altres contextos. Veg.: ALCARAZ RAMOS, M. El pincel de Ticiano en la edad electrónica: televisión, cultura y estado de bienestar. En: diversos autors, Televisió i cultura. RTVV, València, 1995, pàg. 35.

10 S'ha indicat que entre el 1975 i el 1982 es van rodar a Espanya poc més de mil pel·lícules, a les quals caldria sumar un nombre indeterminat d'obres de cinema alternatiu, i també les prohibides anteriorment que ara s'estrenaven. TRENAZADO ROMERO, M. El cine español de la transición: desmontando a Franco. En: QUIROSACHEYROUZE I MUÑOZ, R. (coord.) Historia de la Transición en España. Los inicios del proceso democratizador, Biblioteca Nueva, Madrid, 2007, pàg. 453 i 439.

11 El text, en el marc de molts altres documents legals i polítics de l'època, es pot veure en: HERRERO DE MIÑÓN, M. (Ed.) La Transición democrática en España/A Transiçâo democática em Espanha (vol. II). Fundació BBV-Fundaçao Mario Soares, Madrid, 1999, pàg. 437 i seg.

12 Un altre reial decret, d'11 de novembre del mateix any 1977, va aprofundir en l'abolició de la censura cinematogràfica, si bé amb cauteles, com ara instituir la categoria de pel-lícules $\mathrm{S}$ per a «les pel-lícules que pogueren ferir la sensibilitat del públic». D'altra banda, el 24 de febrer del 1982 es van autoritzar les sales X.

13 Amb feliç concisió s'ha parlat d'aquest fenomen com de «la descompressió eròtica» en un article recent, amb unes reflexions molt encertades sobre aquesta qüestió: GUBERN, R. La fiesta de la cultura. En: AA.VV., 2007: 163 i seg. 
amb aquesta qüestió que amb els greus al·legats a favor de la democràcia —que tampoc no van abundar tant- o amb diatribes antifranquistes - que van arribar en comptagotes. El resum màxim d'aquesta tendència és que, si el 1975 la pel-lícula espanyola més vista va ser la compromesa Furtivos (1.655.765 espectadors), I'any següent, aquest lloc el va ocupar la mítica La trastienda, amb el primer nu integral (2.192.957 espectadors) ${ }^{14}$. Tampoc és sorprenent que, en el marc de certs desconcerts, l'aprofitament de la política naixent fóra el terreny triat per a la referència en clau sexual, incloent-hi alguns dels títols que, sobre el paper, més remetien a l'esfera estrictament política. Així, El consenso al-ludirà als enfrontaments en una ciutat costanera entre prostitutes i dames piadoses; El diputado es dedicarà a problemes relacionats amb I'homosexualitat; Vote a Gundisalvo serà recordada, primer de tot, per la imatge nua d'Ivonne Sentis davant d'un pòster de Felipe González... De la mateixa manera, no deixa de ser simptomàtic que algunes de les primeres produccions de Pedro Almodóvar en super-8 es titularen Sodoma o Folle...folle..., Fólleme Tim (GUBERN, 2007: 173).

I és que, a bona part de la societat li interessava més el que podia veure que el que es podia dir. No van faltar tampoc els intel-lectuals que denunciaven aquesta banalització de l'espai audiovisual... amb el risc consegüent que el seu missatge es barrejara amb el dels capdavanters de la lluita contra el llibertinatge. En definitiva, l'epidèmia del destape no va ser sinó una mostra més de com era d'urgent normalitzar la nova realitat, que tampoc podia defugir les necessitats mercantils i crematístiques de les productores. D'altra banda, el fenomen tenia el seu precedent en els gloriosos temps d'un landismo que caldria inscriure en l'anàlisi sobre la crisi de l'imaginari del tardofranquisme, com a retrat d'una societat acomplexada, reprimida, però expectant; i, temorosa, agafada, alhora, als anhels d'alliberament i a valors reaccionaris.

És clar que també es pot fer un altre enfocament: el del cinema de la memòria. $O$, més ben dit, el de la funció del cinema en la reconstrucció d'una memòria col·lectiva violada15. Per això ens hem acostumat a entendre el cinema en la Transició com un cinema prioritàriament dirigit cap a la Guerra Civil i el franquisme. Per això hem admès que, en realitat, hi ha molt poc cinema de la Transició sobre la Transició —un poc de Juan Antonio Bardem, Inmanol Uribe o de José Luis Garci.... El paper d'El desencanto (1976), de Jaime Chavarri, és peculiar: encara que moltes vegades s'ha vist com la metàfora directa d'un estat d'ànim, de decepció, que va contagiar la societat espanyola, en realitat aquesta situació no es produir, llevat probablement d'alguns segments hiperpolititzats de la militància partidista d'esquerres; però queda l'exemple de com una producció cinematogràfica va servir per a construir, a posteriori, una part important del relat principal sobre la Transició.

Així doncs, el ventall de paradoxes s'obri, perquè ens remet a unes quantes convencions de l'època sobre la dialèctica entre la justícia del record i l'oportunitat de l'oblit i del silenci: entre aquests dos pols circularà la memòria col·lectiva en la Transició, i aquesta circumstància també es reflectirà, per activa i per passiva, en les temàtiques i en les maneres narratives d'aquest període (TRENZADO, 2007: 439i seg.). Sabem que el cinema és història, però que

14 Vegeu els estudis d'espectadors en: AGUILAR FERNÁNDEZ, P., 2007, annex I, 113. S'usen per a comentaris ulteriors.

15 Sobre la qüestió general de la memòria històrica i la cultura, vegeu: COLMEIRO, J. F. Memoria histórica e identidad cultural. De la postguerra a la postmodernidad. Anthropos, Barcelona, 2005. Passim. 
no podem demanar que la substituïsca com a saber professional, per això és indicatiu de les fronteres entre la cultura i la política que, deixant de banda alguna excepció, els èxits més grans seran els usos nostàlgics de Basilio Martín Patino en les seues Canciones para después de una guerra i les estratègies metafòriques i elusives de Luis G. Berlanga en la saga de La escopeta nacional i en La vaquilla, la pel-lícula de més acceptació popular sobre la Guerra Civil, i que s'ha interpretat com la representació cinematogràfica de l'acord tàcit, consensuat per tothom, que tots vam ser culpables del desastre. I tampoc hem d'oblidar, és clar, l'èxit d'algunes produccions basades en les inefables novel.les barates neofranquistes de Fernando Vizcaíno Casas ${ }^{16}$ que operaven com el revés de la moneda, com a explicitació de l'enyorança davant d'un sistema de seguretats agitat per tanta moguda, però, també, la sorpresa davant de la inauguració de pràctiques consubstancials a la democràcia, com els partits, les eleccions, etc.

Hi ha una fotografia ${ }^{17}$ de l'octubre de 1981 que em sembla una al·legoria de la Transició cultural que comente. Plasma la presentació del recuperat Guernica en el Casón del Buen Retiro. Dos terços de la imatge estan ocupats pel quadre, amb tota la força visual i la potència, llavors més intensa que ara, que irradia el seu missatge. No obstant això, l'obra està interferida per un cristall protector. L'altre terç de la imatge està ocupada per una bandera espanyola —encara imprescindible en cada acte social_ ornada per l'àguila franquista... i per un guàrdia civil, amb el tricorni lluent, la barba retallada —un signe de modernitat—... i subfusell en bandolera. La barreja de signes que, a priori, consideraríem excloents, és d'una rotunditat extraordinària, i si la fotografia no pertanguera al gènere periodístic, si fóra l'obra d'un creador imaginatiu, seria un somni de transgressió, la vulneració conscient de qualsevol sistema icònicament assentat. Doncs bé: en certa manera això va ser la Transició. Un això cultural que era potència i acte, explosió de llibertat i temor de trobar els seus límits massa prop; un revulsiu simbòlic que necessitava tant les paràboles existents que calia deconstruir —de vegades per camins equívocs-, com la instauració d'altres de noves, la recuperació del passat tant com la domesticació del present. El cinema en va ser el principal narrador, encara que, potser, no el millor narrador. I en aquest paper va contribuir a generar el relat social sobre la Transició, amb tots els seus encisos i tots els seus paranys. Captiu de les mateixes contradiccions de l'època, quan el tornem a visitar ens deixa amb la sensació que, encara, no ha dit l'última paraula, que els temps estan madurs per a altres reconsideracions, per a altres imatges.

16 El 1980, la pel-lícula espanyola amb més nombre d'espectadors (1.212.025) va ser $Y$ al tercer año resucitó, per davant d'Ópera prima, Polvos mágicos, Los energéticos i La muchacha de las bragas de oro ... un bon retrat dels gustos i de les preferències generals de la societat espanyola i de les tendències en les produccions nacionals. Altres obres basades en textos de Fernando Vizcaíno Casas van ser La boda del señor cura (1979) i De camisa vieja a chaqueta nueva (1982).

17 La fotografia és de Manuel Pérez Barriopedro, per a EFE. 